\title{
Smaller clinical trials for decision making; using p-values
}

\section{could be costly [version 1; peer review: 1 approved with}

\section{reservations]}

\author{
Nicholas Graves (iD), Adrian G. Barnett (D1), Edward Burn², David Cook³ \\ ${ }^{1}$ Institute of Health and Biomedical Innovation, Queensland University of Technology, Brisbane, QLD, 4059, Australia \\ ${ }^{2}$ Nuffield Department of Orthopaedics, Oxford University, Oxford, OX3 7LD, UK \\ ${ }^{3}$ Princess Alexandra Hospital, Brisbane, Brisbane, QLD, 4102, Australia
}

\author{
V1 First published: 02 Aug 2018, 7:1176 \\ https://doi.org/10.12688/f1000research.15522.1 \\ Latest published: 27 Sep 2018, 7:1176 \\ https://doi.org/10.12688/f1000research.15522.2
}

\section{Abstract}

Background: Clinical trials might be larger than needed because arbitrary high levels of statistical confidence are sought in the results. Traditional sample size calculations ignore the marginal value of the information collected for decision making. The statistical hypothesis testing objective is misaligned with the goal of generating information necessary for decision-making. The aim of the present study was to show that a clinical trial designed to test a prior hypothesis against an arbitrary threshold of confidence may recruit too many participants, wasting scarce research dollars and exposing participants to research unnecessarily.

Methods: We used data from a recent RCT powered for traditional rules of statistical significance. The data were also used for an economic analysis to show the intervention led to cost savings and improved health outcomes. Adoption represented a good investment for decision-makers. We examined the effect of reducing the trial's sample size on the results of the statistical hypothesis-testing analysis and the conclusions that would be drawn by decision-makers reading the economic analysis.

Results: As the sample size reduced it became more likely that the null hypothesis of no difference in the primary outcome between groups would fail to be rejected. For decision-makers reading the economic analysis, reducing the sample size had little effect on the conclusion about whether to adopt the intervention. There was always high probability the intervention reduced costs and improved health. Conclusions: Decision makers managing health services are largely invariant to the sample size of the primary trial and the arbitrary $p$ value of 0.05 . If the goal is to make a good decision about whether the intervention should be adopted widely, then that could have been achieved with a much smaller trial. It is plausible that hundreds of millions of research dollars are wasted each year recruiting more

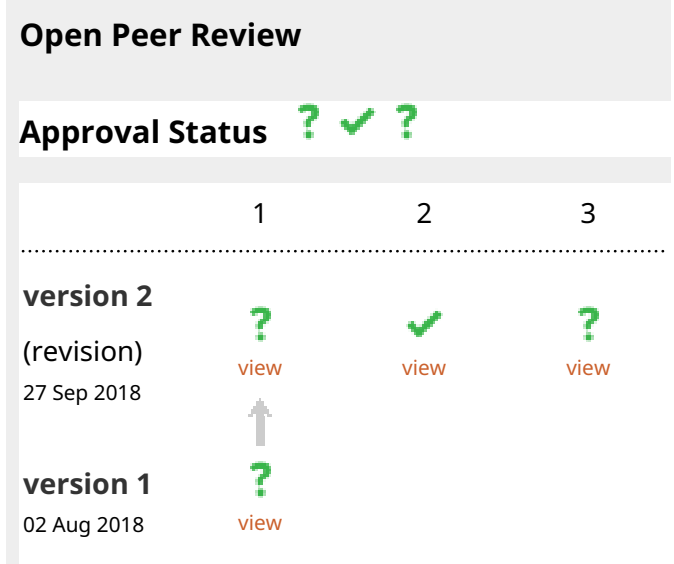

1. Stephen Senn iD, Luxembourg Institute Of Health, Strassen, Luxembourg University of Sheffield, Sheffield, UK

2. Steven A Julious, University of Sheffield, Sheffield, UK

3. Daniel Benjamin Mark, Duke University Medical Center, Durham, USA Any reports and responses or comments on the article can be found at the end of the article. 
participants than required for RCTs.

\section{Keywords}

decision making, RCT, sample size, waste in research

Corresponding author: Nicholas Graves (n.graves@qut.edu.au)

Author roles: Graves N: Conceptualization, Formal Analysis, Funding Acquisition, Investigation, Methodology, Project Administration, Supervision, Validation, Writing - Original Draft Preparation, Writing - Review \& Editing; Barnett AG: Conceptualization, Formal Analysis, Methodology, Software, Supervision, Writing - Review \& Editing; Burn E: Conceptualization, Data Curation, Formal Analysis, Methodology, Writing - Review \& Editing; Cook D: Conceptualization, Methodology, Supervision, Writing - Review \& Editing

Competing interests: No competing interests were disclosed.

Grant information: The author(s) declared that no grants were involved in supporting this work.

Copyright: $\odot 2018$ Graves $\mathrm{N}$ et al. This is an open access article distributed under the terms of the Creative Commons Attribution License , which permits unrestricted use, distribution, and reproduction in any medium, provided the original work is properly cited. Data associated with the article are available under the terms of the Creative Commons Zero "No rights reserved" data waiver (CC0 1.0 Public domain dedication).

How to cite this article: Graves N, Barnett AG, Burn E and Cook D. Smaller clinical trials for decision making; using p-values could be costly [version 1; peer review: 1 approved with reservations] F1000Research 2018, 7:1176

https://doi.org/10.12688/f1000research.15522.1

First published: 02 Aug 2018, 7:1176 https://doi.org/10.12688/f1000research.15522.1 


\section{Introduction}

Informed patients, thoughtful clinicians and rational health planners make decisions about the services and treatments provided using the best information available, and all decisions are made under conditions of uncertainty ${ }^{1,2}$. We examine a situation where sufficient evidence arises from a clinical trial to inform a decision about changing services before the conventional statistical stopping point for a clinical trial is reached. This paper is about the tension between the 'precision' and the 'impact' of a scientific measurement ${ }^{3}$ and how that tension might dictate the sample size of a clinical trial.

Imagine a new treatment is compared against the best contemporary alternative in a well conducted randomised controlled trial (RCT). The design requires 800 participants in total based on a standard sample size calculation of 5\% type 1 error and $80 \%$ power. The new treatment is more efficacious, prolongs life of high quality and saves more money than it costs to implement. The evidence to support these conclusions can be seen in the data after only 200 trial participants have been recruited, but primary outcomes are not yet statistically significant. Clinical equipoise, the cornerstone of ethical treatment allocation is lost, yet the conventions of hypothesis testing and arbitrary power calculation demand a further 600 participants are recruited. The information arising from the additional 600 participants is unlikely to change the actions of a rational decision maker who wishes to adopt the new treatment. Yet scarce research funds are used up meaning opportunities to fund other research are lost, and some patients have been consented and allocated to a treatment that we could not recommend, nor would we chose for ourselves or our families.

The utility of clinical trials for those managing health services and making clinical decisions is under debate and traditional paradigms are being challenged ${ }^{4}$. The chief claim of this paper is that an RCT designed to test a hypothesis using traditional rules of inference might have more participants than required, if the goal is to make a good decision. Waste in research arises from routine use of arbitrary levels of statistical confidence ${ }^{5}$ and because the trial data are considered in isolation ${ }^{6}$. The marginal value of the information acquired for the purpose of making a good decision is not made explicit. Important information for the purpose of decision making often lies outside the clinical trial process. The plausibility of our claim is demonstrated by re-analysing a recent $\mathrm{RCT}^{7}$.

\section{Choosing a sample size for hypothesis testing}

For the design of superiority trial, the aim is to have a high likelihood of sufficient evidence to confidently reject a null hypothesis that two treatments are equivalent when treatments differ by a specified difference. This difference is usually based on either clinical importance or a best guess of the true treatment effect. Inference based on this approach has two types of potential errors. A false-positive or type I error of rejecting the null hypothesis when there is no difference, with probability $\alpha$. A false negative or type II error of not rejecting the null hypothesis when there is an effect, with probability $\beta$. The sample size of the trial is calculated to give an acceptable type I error rate and power (1- $\beta$ ), typically 0.05 for $\alpha$ and 0.8 to 0.9 for the power. The final analysis summarises the incompatibility between the data and the null hypothesis ${ }^{8}$. If the p-value is below the standard 5\% limit the null hypothesis of no effect is rejected. A 'statistically significant' result is then celebrated and typically used to support a decision to make a change to health services.

\section{Choosing a sample size for decision making}

We assume the objective of decision-makers who manages health services is to improve outcomes for the populations they serve. Because this challenge will be addressed with finite resources not every service or new technology can be made available for a population. Decision-makers therefore require knowledge of the health foregone from not funding services displaced by the services that are funded ${ }^{9}$. The services that are provided should generate more health benefits per dollar of cost when compared to those that are not. With this criterion satisfied the opportunity cost from the services not provided is minimised. A rational decision maker will logically follow these rules: do not adopt programmes that worsen health outcomes and increase cost; adopt programmes that improve health outcomes and decrease costs; and, when they face a situation of increased cost for increased health outcomes they prioritise programmes that provide additional health benefits for the lowest extra $\operatorname{cost}^{10}$. They will continue choosing cost-effective services until available health budgets are exhausted. An appropriate and generic measure of health benefit is the quality adjusted life year (QALY) ${ }^{11}$. While this approach does not consider how health benefits are distributed among the population there is a framework for including health inequalities in the economic assessment of health care programmes ${ }^{12}$.

In choosing a sample size for a clinical trial to evaluate a new service or technology a decision-maker will consider the uncertainty in the conclusion about how costs and health benefits change by adoption. The aim is to reduce the likelihood of making the wrong decision. They will make rational and good decisions, and they will manage uncertainty rather than demand an arbitrarily high probability of rejecting a null hypothesis. Methods are available to estimate the expected value of information and so the optimal sample size for a trial is dependent on the context specific costs and benefits of acquiring extra information ${ }^{13}$. Each decision is context dependent and the 'one size fits all' approach to sample size calculation is arbitrary and potentially wasteful. This holistic approach should be a priority for designing, monitoring and analysing clinical trials.

\section{Methods}

\section{The TEXT ME RCT: A case study}

A case study to illustrate the differing evidential requirements of the 'hypothesis-testing' and 'decision-making' approaches is provided by the RCT of the Tobacco, Exercise and Diet Messages (TEXT ME) intervention ${ }^{14}$. This health services program targeted multiple influential risk factors in patients with coronary heart disease, with SMS text messages. Advice and motivation was provided to improve health behaviours and it was supplementary to usual care. The hypothesis was that the intervention would lower plasma low-density lipoprotein cholesterol by 
$4.5 \mathrm{mg} / \mathrm{dL}$ at 6 months for participants compared with those receiving usual care ${ }^{15}$. The required sample size was 704 participants for $90 \%$ power $^{15}$ and the trial recruited and randomised 710 participants 7 . The mean difference between the intervention and control group was $-5 \mathrm{mg} / \mathrm{dL},(95 \% \mathrm{CI}-9$ to $0 \mathrm{mg} / \mathrm{dL})$. With a p-value of 0.04 , the null hypothesis was rejected. Evidence for health effects were also sought on other biomedical and behavioural risk factors, quality of life, primary care use and re-hospitalisations. Clinically and statistically significant effects were also found for systolic blood pressure (mean difference $-8 \mathrm{mmHg}, \mathrm{p}<0.001)$, body mass index $\left(-1.3 \mathrm{~kg} / \mathrm{m}^{2}, \mathrm{p}<0.001\right)$ and current smoking (relative risk of $0.61, \mathrm{p}<0.001$ ).

The TEXT ME trial data were used to inform an economic evaluation of the potential change to costs and health benefits measured in quality adjusted life years to the community from a decision to adopt the programme ${ }^{16}$. The observed differences in low-density lipoprotein cholesterol, systolic blood pressure and smoking were combined with reliable external epidemiological evidence to estimate the reduction in acute coronary events, myocardial infarction and stroke and were extrapolated over the patients expected remaining life times. The costs of providing the intervention, the projected costs of the treatment of acute events and general primary care use and expected mortality were all informed by data sources external to the primary trial ${ }^{16}$. The findings revealed that TEXT ME was certainly going to lead to better health outcomes and cost savings. The conclusion was that a rational decision-maker should fund and implement the TEXT ME program. Once available an informed clinician would then recommend TEXT ME to coronary patients, and enough patients would sign up to create benefits for individuals and the health system. Using the TEXT ME study, we consider whether the same decision could have been made at an earlier stage with fewer participants enrolled in the primary trial.

\section{Data analysis}

We examine the effect of a reduced sample size on the results of both the hypothesis-testing analysis for differences in low-density lipoprotein cholesterol, and the economic evaluation of the intervention. From the original 710 participants, smaller samples between 100 and 700 patients in increments of 100 were considered with the resampling done with replacement. The 'p-value' and 'economic' analyses were re-run using the data provided by the randomly selected patients, and this process was repeated 500 times for each sample size. The simulations and figures were created using $\mathrm{R}$ (version 3.1.0). The code is available on GitHub https://github.com/agbarnett/smaller.trials but we are unable to share the primary data from the TEXT ME RCT.

\section{Results}

The effect of reducing the sample size for hypothesis-testing objectives was to simulate studies that traditional hypothesis testing approaches would deem underpowered, see Figure 1.

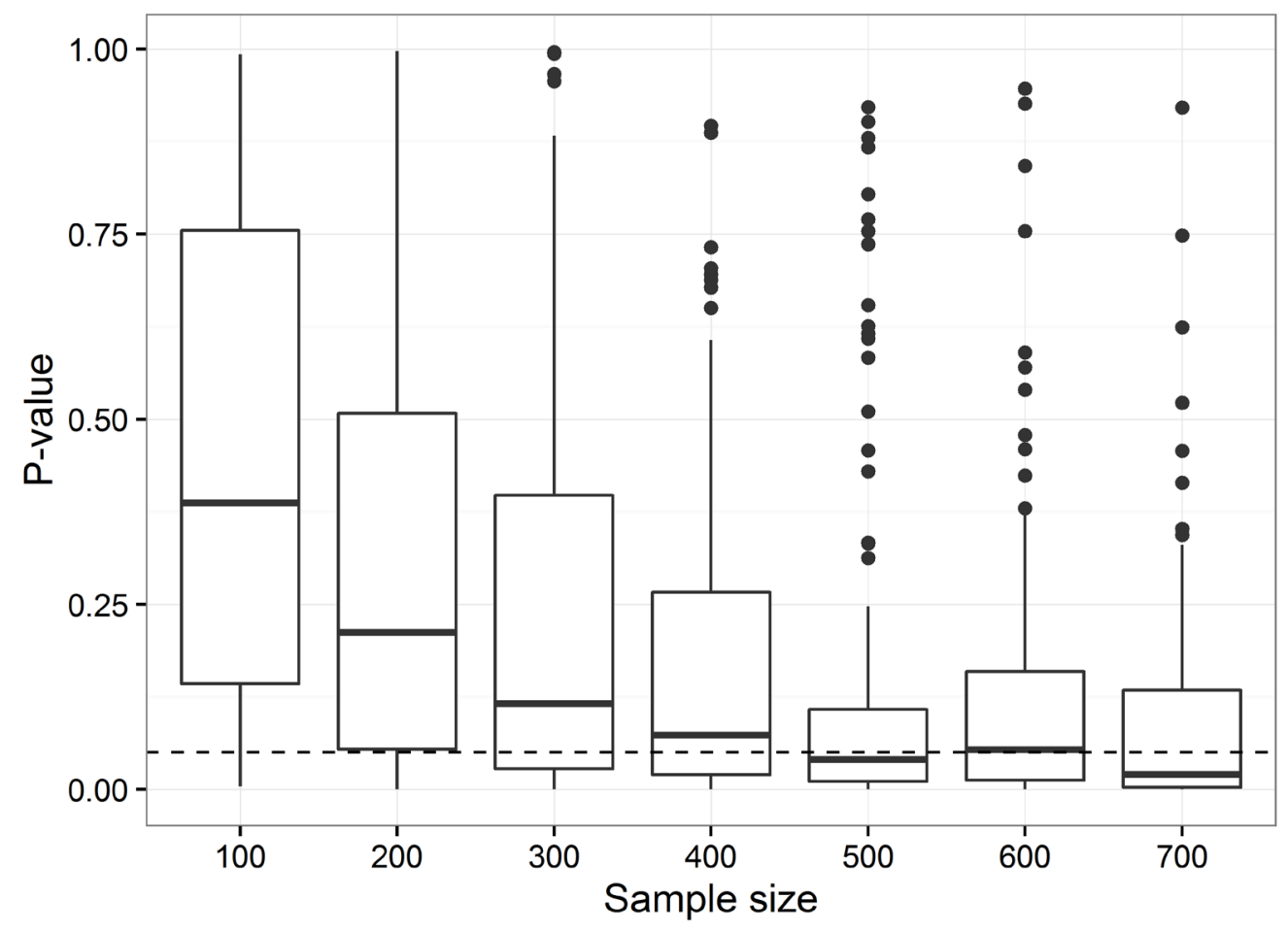

Figure 1. P-values increase as sample sizes decrease for the observed differences in low-density lipoprotein cholesterol (based on 500 simulations per sample size). The dotted horizontal line is the standard $5 \%$ threshold. The boxes are the 25th and 75 th percentiles with the median as the central line. The upper whisker extends from the third quartile to the largest value no further than $1.5^{*} \mathrm{IQR}$ from the quartile (where IQR is the inter-quartile range). The lower whisker extends from the 1st quartile to the smallest value at most 1.5 * IQR of the quartile. Data beyond the end of the whiskers are called 'outlying' points and are plotted individually. 
Only for a sample size of 500 participants or more would the majority of trials find a statistically significant difference in average low-density lipoprotein cholesterol between groups (Figure 1). Even at a sample size of 700 around $30 \%$ of trials would be expected to make the 'wrong' inference of not rejecting the null hypothesis. This is consistent with a priori analytic estimates of sample size to address the hypothesis.

To inform decision making using cost-effectiveness as the criterion, reducing the sample size has little effect on the conclusion of whether to fund, recommend and participate in TEXT ME, see Figure 2. For every simulation for each sample size the decision to adopt TEXT ME led to cost savings shown on the $\mathrm{y}$-axis and gains to health, measured by QALYs shown on the $\mathrm{x}$-axis.

A sample size of 100 or more in the primary trial would convince a risk neutral and rational decision maker that TEXT ME is both cost-saving and health improving, and so should be adopted. The imprecision surrounding this inference increases as the sample size reduces, but the decision-making inference does not change. If the goal is to make a good decision about whether TEXT ME should be adopted widely, then that could have been achieved with a much smaller trial, one that enrolled as few as 100 patients. This would have been a cheaper and quicker research project releasing scarce research dollars for other important projects.

Dataset 1. Data used for a simulation of Figure 2

http://dx.doi.org/10.5256/f1000research.15522.d212377

\section{Discussion}

RCTs have become "massive bureaucratic and corporate enterprises, demanding costly infrastructure for research design, patient care, record keeping, ethical review, and statistical analysis" $"$. A single phase 3 RCT could today cost $\$ 30$ million or more ${ }^{18}$ and take several years from inception to finalisation. These trials are powered for arbitrary rules of statistical significance. Critics of this approach ${ }^{3}$ argue "that some of the sciences have made a mistake, by basing decisions on statistical significance" and that "in daily use it produces unchecked a loss of jobs, justice, profit, and even life". The mistake made by the so called 'sizeless scientist' is to favour 'Precision' over 'Oomph'. A 'sizeless scientist' is more interested in how precisely an outcome is estimated and less interested in the size of the implications for society or health services of any observed change in the outcome. They do not appear interested in the facts that "significant does not mean important and insignificant does not mean unimportant". Even experts in statistics have been shown to interpret evidence poorly, based on whether the p-value crosses the threshold of $5 \%$ for statistical significance ${ }^{19}$.

Researchers are calling for a shift towards applied research designed for decision making ${ }^{20}$. Patients, clinicians and payers of health care are interested in whether some novel treatment or health programme should be adopted over the alternatives. There are many choices to be evaluated and many useful clinical trials to be undertaken, yet research budgets to support this are insufficient $^{21}$. Funding a larger number of smaller trials to enable correct decisions about how to organise health services more frequently is a sensible goal.

A hypothesis-testing approach maintains that a uniform level of certainty around these decisions is desirable, and needed by all stakeholders: managers, clinicians and patients. Yet the costs and benefits of every decision made are context-specific. Striving to eliminate uncertainty is likely to be inefficient use of research funding, where the benefit of achieving a given level of certainty is low or the prescribed precision unnecessary. Decision-making should address the costs and benefits throughout the life cycle of an intervention ${ }^{22}$, with consideration of whether decisions could be made based on current evidence and whether additional research needs to be undertaken ${ }^{23}$.

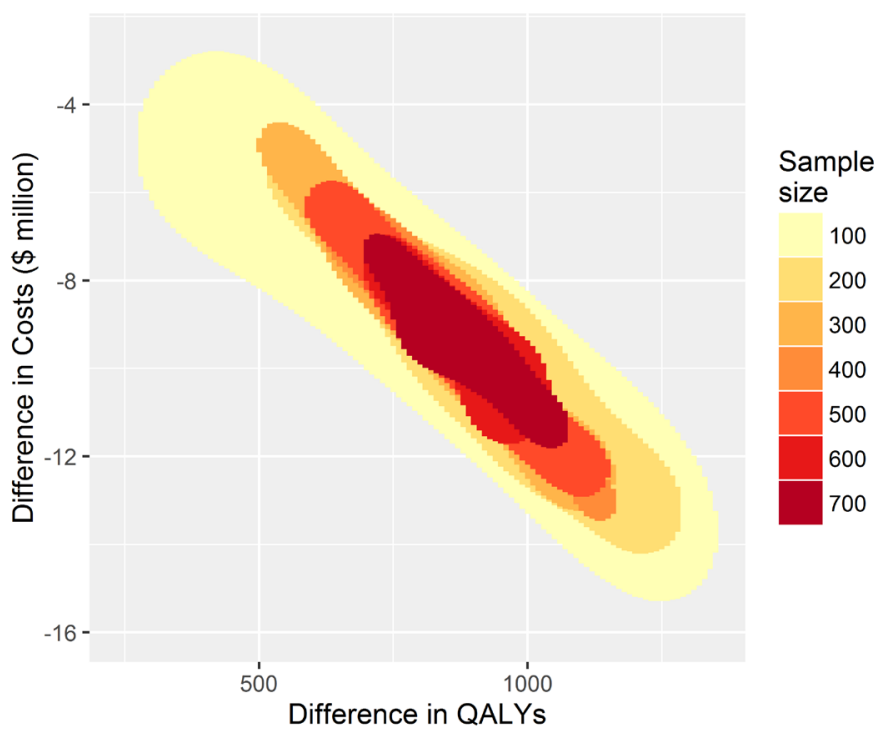

Figure 2. The conclusion for decision-making becomes more uncertain but does not change with decreasing sample size. The $X$-axis shows the QALY gains for TEXT ME over usual care, and the $y$-axis shows the cost savings. 
Other considerations for decision making under conditions of uncertainty have been established and reviewed in detail ${ }^{24}$. Our observations contradict advice by Nagendran et al. ${ }^{25}$ who suggest researchers aim to "conduct studies that are larger and properly powered to detect modest effects". This approach promotes using p-values for decision making without a more encompassing evaluation of all outcomes that are relevant for decision-making.

We suggest the decision making approach to sample size calculation would often lead to smaller trials, but not always. If rare adverse events had a substantial impact on cost and health outcomes the trial may be larger than a hypothesis testing trial powered for a single outcome, which was not the adverse event. This may especially be the case for trials of new drugs. There are some good arguments against smaller trials. A large trial with lots of data might help future proof an adoption decision. If costs, frequencies of adverse events or baseline risks change over time then a large trial might render sufficient information to defend the adoption decision in the future as compared to a small trial. There might also not be another opportunity to run an RCT, for ethical or funding reasons, and so gathering a lot of data when the chance arises could be wise. Smaller trials, despite being well designed, might find a positive result that overestimates the real effect $^{26}$. This may have happened with our example of TEXT ME and a more conservative estimate of the intervention effect would likely come from a meta-analysis or repeated trial. Indeed Prasad et al. ${ }^{27}$ found from 2,044 articles published over 10 years in a leading medical journal, 1,344 were about a medical practice, 363 of them tested an established medical practice and for $146(40 \%)$ the finding was that practice was no better or worse than the comparator implying a reversal of practice. Those who deliver health services are unlikely to be rational and risk neutral. There is often scepticism and inertia when a change to practice is suggested and some clinicians will only change when evidence is overwhelming. Lau et $a .^{28}$ did a cumulative meta-analysis of intravenous streptokinase for acute myocardial infarction with mortality as the primary outcome. They showed the probability the treatment reduced mortality was greater than $97.5 \%$ by 1973 after 2,432 patients had been enrolled in eight trials. By 1977, after 4,084 patients had been enrolled in thirteen trials the probability the treatment was effective was more than 99.5\%. By 1988, 36 trials had been completed with 36,974 patients included confirming the previous conclusion.

Our case study demonstrates - for a single carefully conducted trial - that more information might have been collected than was necessary for a good decision to be made about a decision to adopt the intervention. We did not cherry pick this trial, but selected it because it was a recent economic analysis and had broad implications for health. The differences in necessary sample sizes and evidence will depend on context and design of trials. It might often be that smaller and so faster and cheaper trials are sufficient for good decision-making. This would release scarce research dollars that funding bodies could use for other valuable projects. Our approach is part of the drive toward increasing the value of health and medical research, which currently has a poor return with an estimated $85 \%$ of investment wasted $^{29}$. Further, as adaptive trials gain traction, decision based designs provide flexibility, facilitating faster evolution of implementable findings.

\section{Data availability}

The datasets used and/or analysed for the TEXT ME trial are not publicly available due to data sharing not being approved by the local ethics committee. To access the data, the corresponding author of the primary trial should be contacted (cchow@georgeinstitute.org.au).

A random sample of the TEXT ME clinical trial data that has similar features to the TEXT ME data is provided in the code used to create the simulations and figures, which is available on GitHub: https://github.com/agbarnett/trials.smaller

Archived code as at time of publication: http://doi.org/10.5281/ zenodo. $1322459^{30}$

Dataset 1: Data used for a simulation of Figure 2. DOI, 10.5256/ f1000research.15522.d212377 ${ }^{31}$

\section{Competing interests}

No competing interests were disclosed.

\section{Grant information}

The TEXT ME trial was supported by peer-reviewed grants from the National Heart Foundation of Australia Grant-in-Aid (G10S5110) and a BUPA Foundation Grant. We acknowledge the team who designed and conducted the TEXT ME trial and allowed us to re-analyse the data for the purpose of this paper: Clara Chow, Julie Redfern, Graham Hillis, Aravinda Thiagalingam, Stephen Jan, Maree Hackett, Robyn Whittaker. They did not provide editorial input or endorsement. The TEXT ME trial was administered by The George Institute for Global Health, Sydney Medical School, University of Sydney, Sydney, Australia.

Regarding the extra activity for this paper the authors declare that no grants were involved in supporting this work.
1. Hunink MM, Weinstein MC, Wittenberg E, et al:: Decision making in health and medicine: integrating evidence and values. Cambridge University Press; 2014. Reference Source

2. Tversky A, Kahneman D: The framing of decisions and the psychology of choice. Science. 1982; 211(4481): 453-8. PubMed Abstract | Publisher Full Text

3. Ziliak S, McCloskey D: The Cult of Statistical Significance: How the Standard
Error Costs Us Jobs, Justice, and Lives. Ann Arbor, Ml.: The University of Michigan Press; 2008.

Publisher Full Text

4. Woodcock J, Ware JH, Miller PW, et al:: Clinical Trials Series. N Engl J Med. 2016; 374(22): 2167.

Publisher Full Text

5. Claxton $\mathrm{K}$ : The irrelevance of inference: a decision-making approach to the 
stochastic evaluation of health care technologies. $J$ Health Econ. 1999; 18(3): 341-64.

PubMed Abstract | Publisher Full Text

6. Goodman SN: Toward evidence-based medical statistics. 1: The $P$ value fallacy Ann Intern Med. 1999; 130(12): 995-1004. PubMed Abstract | Publisher Full Text

7. Chow CK, Redfern J, Hillis GS, et al:: Effect of Lifestyle-Focused Text Messaging on Risk Factor Modification in Patients With Coronary Heart Disease: $\mathrm{A}$ Randomized Clinical Trial. JAMA. 2015; 314(12): 1255-63. PubMed Abstract | Publisher Full Text

8. Wasserstein RL, Lazar NA: The ASA's statement on p-values: context, process, and purpose. Am Stat. 2016; 70(2): 129-33. Publisher Full Text

9. Claxton K, Palmer S, Longworth L, et al.: A Comprehensive Algorithm for Approval of Health Technologies With, Without, or Only in Research: The Key Principles for Informing Coverage Decisions. Value Health. 2016; 19(6): 885-91.

PubMed Abstract | Publisher Full Text

10. Phelps $\mathrm{CE}$, Mushlin Al: On the (near) equivalence of cost-effectiveness and cost-benefit analyses. Int J Technol Assess Health Care. 1991; 7(1): 12-21. PubMed Abstract | Publisher Full Text

11. Torrance GW: Measurement of health state utilities for economic appraisal. $J$ Health Econ. 1986; 5(1): 1-30. PubMed Abstract | Publisher Full Tex

12. Asaria M, Griffin S, Cookson R: Distributional Cost-Effectiveness Analysis: $\boldsymbol{A}$ Tutorial. Med Decis Making. 2016; 36(1): 8-19. PubMed Abstract | Publisher Full Text | Free Full Text

13. Claxton K: Bayesian approaches to the value of information: implications for the regulation of new pharmaceuticals. Health Econ. 1999; 8(3): 269-74. PubMed Abstract | Publisher Full Text

14. Redfern J, Thiagalingam A, Jan S, et al:: Development of a set of mobile phone text messages designed for prevention of recurrent cardiovascular events. Eur J Prev Cardiol. 2014; 21(4): 492-9. PubMed Abstract | Publisher Full Text

15. Chow CK, Redfern J, Thiagalingam A, et al:: Design and rationale of the tobacco, exercise and diet messages (TEXT ME) trial of a text message-based intervention for ongoing prevention of cardiovascular disease in people with coronary disease: a randomised controlled trial protocol. BMJ Open. 2012; 2(1): e000606.

PubMed Abstract | Publisher Full Text | Free Full Text

16. Burn $\mathrm{E}$, Nghiem $\mathrm{S}$, Jan $\mathrm{S}$, et al: Cost-effectiveness of a text message programme for the prevention of recurrent cardiovascular events. Heart. 2017 103(12): 893-4.

PubMed Abstract | Publisher Full Text

17. Bothwell LE, Greene JA, Podolsky SH, et al:: Assessing the Gold StandardLessons from the History of RCTs. N Engl J Med. 2016; 374(22): 2175-81. PubMed Abstract | Publisher Full Text

18. Sertkaya A, Birkenbach A, Berlind A, et al.: Examination of clinical trial costs and barriers for drug development: report to the Assistant Secretary of Planning and Evaluation (ASPE). Washington, DC: : Department of Health and Human Services; 2014.

Reference Source

19. McShane BB, Gal D: Statistical Significance and the Dichotomization of Evidence. J Am Stat Assoc. 2017; 112(519): 885-95. Publisher Full Text

20. Lieu TA, Platt R: Applied Research and Development in Health Care - Time for a Frameshift. N Engl J Med. 2017; 376(8): 710-3.

PubMed Abstract | Publisher Full Tex

21. Van Noorden R: UK government warned over 'catastrophic' cuts. Nature. 2010; 466(7305): 420-1.

PubMed Abstract | Publisher Full Text

22. Sculpher M, Drummond M, Buxton M: The iterative use of economic evaluation as part of the process of health technology assessment. J Health Serv Res Policy. 1997; 2(1): 26-30. PubMed Abstract | Publisher Full Text

23. Sculpher MJ, Claxton K, Drummond M, et al.: Whither trial-based economic evaluation for health care decision making? Health Econ. 2006; 15(7): 677-87. PubMed Abstract | Publisher Full Text

24. Claxton K, Palmer S, Longworth L, et al.: Informing a decision framework for when NICE should recommend the use of health technologies only in the context of an appropriately designed programme of evidence development. Health Technol Assess. 2012; 16(46): 1-323.

PubMed Abstract | Publisher Full Text

25. Nagendran M, Pereira TV, Kiew G, et al:: Very large treatment effects in randomised trials as an empirical marker to indicate whether subsequent trials are necessary: meta-epidemiological assessment. BMJ. 2016; 355: i5432. PubMed Abstract | Publisher Full Text | Free Full Text

26. Barnett AG, van der Pols JC, Dobson AJ: Regression to the mean: what it is and how to deal with it. Int J Epidemiol. 2005; 34(1): 215-20. PubMed Abstract | Publisher Full Text

27. Prasad V, Vandross A, Toomey C, et al:: A decade of reversal: an analysis of $\mathbf{1 4 6}$ contradicted medical practices. Mayo Clin Proc. 2013; 88(8): 790-8.

PubMed Abstract | Publisher Full Text

28. Lau J, Schmid CH, Chalmers TC: Cumulative meta-analysis of clinical trials builds evidence for exemplary medical care. J Clin Epidemiol. 1995; 48(1): 45-57; discussion 59-60.

PubMed Abstract | Publisher Full Text

29. Chalmers I, Glasziou P: Avoidable waste in the production and reporting of research evidence. Lancet. 2009; 374(9683): 86-9. PubMed Abstract | Publisher Full Text

30. Barnett A: agbarnett/smaller.trials: First release of $\mathbf{R}$ code for smaller clinical trials (Version v1.0). Zenodo. 2018. http://www.doi.org/10.5281/zenodo.1322459

31. Graves N, Barnett AG, Burn E, et al.: Dataset 1 in: Smaller clinical trials for decision making; using p-values could be costly. F1000Research. 2018. http://www.doi.org/10.5256/f1000research.15522.d212377 


\section{Open Peer Review}

\section{Current Peer Review Status: ?}

\section{Version 1}

Reviewer Report 07 September 2018

https://doi.org/10.5256/f1000research.16927.r37678

(C) 2018 Senn S. This is an open access peer review report distributed under the terms of the Creative Commons Attribution License, which permits unrestricted use, distribution, and reproduction in any medium, provided the original work is properly cited.

\section{Stephen Senn \\ ${ }^{1}$ Competence Center for Methodology and Statistics, Luxembourg Institute Of Health, Strassen, Luxembourg \\ 2 School of Health and Related Research, University of Sheffield, Sheffield, UK \\ The authors propose that when a clinical trial is sought to inform practical decision-making, conventional standards of 'proof' may be too stringent and in consequence resources may be wasted. They illustrate this by simulating from a particular clinical trial, the TEXT ME trial, using progressively smaller sample sizes and suggest that a useful decision could have been made with fewer patients.}

The general argument presented is interesting and the conclusion that trials are sometimes too big if practical decision making is the object may well be correct. In this respect, a key distinction was made just over 50 years ago by Schwartz and Lelouch ${ }^{1}$ between what they called explanatory or pragmatic approaches. In the former case 'proof' of the efficacy of a new treatment may be sought. In the latter case one may simply wish to choose the (plausibly) better of two treatments.

However, unless I have misunderstood what the authors are doing (which I do not exclude but in that case they should clarify this) the simulation is not a valid proof of what they claim, even for the example chosen.

The problem is the following. By simulating from the particular trial results, they are simulating from a universe in which the treatment is effective. This would be true even if the results from the TEXT ME trial had not been 'significant'. It is true of any trial in which the observed results favour the intervention. To see this consider that valid statistical analyses will typically have type I error rates in excess of a chosen nominal value if the mean under the intervention is greater (assuming high values are good) than the mean in the control group in the population in question. Provided that the type I error rate is controlled when this is not the case, this is a desirable property of such tests.

Usually, the population in question is taken to be the population of all possible randomisations of 
the patients. Here, the authors sampled without replacement from the population. The population from which they are sampling is the population of results in the full TEXT ME trial. However, this is a population in which on average the results were better for the intervention.

Hindsight is an exact science but those making practical healthcare decisions are involved in the quite different game of foresight and they need to know whether the decision they are about to make is a reasonable one. This requires their allowing for the possibility that the intervention is useless or even harmful. Thus a mixture of possible situations has to be considered: simulating only from the case where the intervention is beneficial is not adequate.

In fact the precise nature of the mixture envisaged can have a huge effect on the inferences. Recently, a number of authors have called for statistical standards of evidence to be modified in the opposite direction. For instance Benjamin et $a .^{2}{ }^{2}$ have suggested that the standard of $p=0.005$ should be adopted. David Colquhoun ${ }^{3}$ has proposed an even more stringent standard of $\mathrm{P}=0.001$. This flows from the particular approach to Bayesian hypothesis testing which places a lump of probability on no difference between treatments. (See my blog ${ }^{4}$ for a discussion.) In my opinion, these are not good suggestions for a number of reasons, including that such prior distributions are far too informative and that these authors implicitly assume, which is far from obviously the case, that the explanatory purpose of clinical trials is more important than the pragmatic one.

However, I agree entirely with the authors, that as soon as practical decision-making involving economics is involved, it is the value of information that is important. In this connection, I can recommend the work of Forster, Pertile and colleagues ${ }^{5,6}$. See also Burman et al. ${ }^{7}$

Thus, I think to make good their claim, the authors would, at the very least, need to simulate from a universe in which the intervention was not necessarily better than the control. Unless I have misunderstood, this was not the simulation they undertook.

\section{References}

1. Schwartz D, Lellouch J: Explanatory and pragmatic attitudes in therapeutical trials.J Chronic Dis. 1967; 20 (8): 637-48 PubMed Abstract

2. Benjamin D, Berger J, Johannesson $M$, Nosek B, et al.: Redefine statistical significance. Nature Human Behaviour. 2018; 2 (1): 6-10 Publisher Full Text

3. Colquhoun $\mathrm{D}$ : An investigation of the false discovery rate and the misinterpretation of $p$-values. $R$ Soc Open Sci. 2014; 1 (3): 140216 PubMed Abstract | Publisher Full Text

4. Senn SJ: Double Jeopardy: Judge Jeffreys upholds the law. 2015. Reference Source

5. Pertile $P$, Forster $M$, Torre D: Optimal Bayesian sequential sampling rules for the economic evaluation of health technologies. Journal of the Royal Statistical Society: Series A (Statistics in Society). 2014; 177 (2): 419-438 Publisher Full Text

6. Jobjörnsson S, Forster M, Pertile P, Burman CF: Late-stage pharmaceutical R\&D and pricing policies under two-stage regulation.J Health Econ. 2016; 50: 298-311 PubMed Abstract | Publisher Full Text

7. Burman C-F: Decision Analysis in Drug Development. In: Dmitrienko A, Chuang-Stein C, Agostino R, eds. Pharmaceutical Statistics Using SAS: A Practical Guide.Cary: SAS Institute. 2007. 385-428

\section{Is the work clearly and accurately presented and does it cite the current literature?} Partly 
Is the study design appropriate and is the work technically sound?

Partly

Are sufficient details of methods and analysis provided to allow replication by others? Partly

If applicable, is the statistical analysis and its interpretation appropriate?

No

Are all the source data underlying the results available to ensure full reproducibility? Yes

Are the conclusions drawn adequately supported by the results?

No

Competing Interests: No competing interests were disclosed.

Reviewer Expertise: I am a medical statistician with many years experience in dealing with problems associated with drug development and regulation.

I confirm that I have read this submission and believe that I have an appropriate level of expertise to confirm that it is of an acceptable scientific standard, however I have significant reservations, as outlined above.

Author Response 18 Sep 2018

Nicholas Graves, Duke NUS Graduate Medical School, Singapore

The authors propose that when a clinical trial is sought to inform practical decision-making, conventional standards of 'proof' may be too stringent and in consequence resources may be wasted. They illustrate this by simulating from a particular clinical trial, the TEXT ME trial, using progressively smaller sample sizes and suggest that a useful decision could have been made with fewer patients.

The general argument presented is interesting and the conclusion that trials are sometimes too big if practical decision making is the object may well be correct. In this respect, a key distinction was made just over 50 years ago by Schwartz and Lelouch1 between what they called explanatory or pragmatic approaches. In the former case 'proof' of the efficacy of a new treatment may be sought. In the latter case one may simply wish to choose the (plausibly) better of two treatments.

RESPONSE: Thanks for flagging this interesting paper on trials and pragmatic decision making. We certainly agree with them that, "many trials would be better approached pragmatically." We have included this paper in the discussion section.

However, unless I have misunderstood what the authors are doing (which I do not exclude but in that case they should clarify this) the simulation is not a valid proof of what they claim, even for the example chosen.

RESPONSE: Our aim was to illustrate the principles of this approach using a case study rather than provide "proof" that this approach is always better. We have changed the title to 
reflect this.

The problem is the following. By simulating from the particular trial results, they are simulating from a universe in which the treatment is effective. This would be true even if the results from the TEXT ME trial had not been 'significant'. It is true of any trial in which the observed results favour the intervention. To see this consider that valid statistical analyses will typically have type I error rates in excess of a chosen nominal value if the mean under the intervention is greater (assuming high values are good) than the mean in the control group in the population in question. Provided that the type I error rate is controlled when this is not the case, this is a desirable property of such tests.

RESPONSE: We agree, although our approach includes the changes to costs from implementing the TEXT ME intervention, so the mean difference also has to also be practically significant in order to recover these costs.

Usually, the population in question is taken to be the population of all possible randomisations of the patients. Here, the authors sampled without replacement from the population. The population from which they are sampling is the population of results in the full TEXT ME trial. However, this is a population in which on average the results were better for the intervention.

RESPONSE: We sampled with replacement. Using our approach, the group means were not always greater in the intervention group. For the primary outcome of LDL cholesterol, the mean was worse in the TEXT ME sample compared with usual care for around $22 \%$ of simulations when using the smallest sample size of 100 . The mean difference in the secondary outcome of systolic blood pressure was stronger in the original data, and in simulations the mean in the TEXT ME sample was always lower (better) compared with the usual care group.

Hindsight is an exact science but those making practical healthcare decisions are involved in the quite different game of foresight and they need to know whether the decision they are about to make is a reasonable one. This requires their allowing for the possibility that the intervention is useless or even harmful. Thus a mixture of possible situations has to be considered: simulating only from the case where the intervention is beneficial is not adequate.

RESPONSE: Our aim is to provide results that are useful for decision makers, including estimates of uncertainty about the decision.

In fact the precise nature of the mixture envisaged can have a huge effect on the inferences. Recently, a number of authors have called for statistical standards of evidence to be modified in the opposite direction. For instance Benjamin et al.2 have suggested that the standard of $p=0.005$ should be adopted. David Colquhoun3 has proposed an even more stringent standard of $\mathrm{P}=0.001$. This flows from the particular approach to Bayesian hypothesis testing which places a lump of probability on no difference between treatments. (See my blog4 for a discussion.) In my opinion, these are not good suggestions for a number of reasons, including that such prior distributions are far too informative and that these authors implicitly assume, which is far from obviously the case, that the explanatory purpose of clinical trials is more important than the pragmatic one.

RESPONSE: We agree and the tension of the explanatory versus pragmatic trial is a key motivation for this paper. These adjustments to the use of the $p$-value remain focused on the $p$-value and it how can inform decisions. These adjustments have been motivated by prior abuses and misinterpretations of the $p$-value, which is a prosaic statistic. Our approach aims to give decision makers, working under conditions of scarce resources, more 
meaningful statistics regarding changes to costs and health benefits.

However, I agree entirely with the authors, that as soon as practical decision-making involving economics is involved, it is the value of information that is important. In this connection, I can recommend the work of Forster, Pertile and colleagues5,6. See also Burman et al. 7

RESPONSE: Thanks for flagging these interesting papers.

Thus, I think to make good their claim, the authors would, at the very least, need to simulate from a universe in which the intervention was not necessarily better than the control. Unless I have misunderstood, this was not the simulation they undertook.

RESPONSE: We have added just such a simulation, which shows that when there's no treatment benefit there is a positive cost from the intervention that is not outweighed by any quality of life benefit. The cost-effectiveness plot shows clear evidence against adopting the intervention. We have added the methods and results for this new simulation and include Figure 3.

\section{References}

1. Schwartz D, Lellouch J: Explanatory and pragmatic attitudes in therapeutical trials.J Chronic Dis. 1967; 20 (8): 637-48 PubMed Abstract

2. Benjamin D, Berger J, Johannesson M, Nosek B, Wagenmakers E, Berk R, Bollen K, Brembs B, Brown L, Camerer C, Cesarini D, Chambers C, Clyde M, Cook T, De Boeck P, Dienes Z, Dreber A, Easwaran K, Efferson C, Fehr E, Fidler F, Field A, Forster M, George E, Gonzalez R, Goodman S, Green E, Green D, Greenwald A, Hadfield J, Hedges L, Held L, Hua Ho T, Hoijtink $H$, Hruschka D, Imai K, Imbens G, Ioannidis J, Jeon M, Jones J, Kirchler M, Laibson D, List J, Little R, Lupia A, Machery E, Maxwell S, McCarthy M, Moore D, Morgan S, Munafó M, Nakagawa S, Nyhan B, Parker T, Pericchi L, Perugini M, Rouder J, Rousseau J, Savalei V, Schönbrodt F, Sellke T, Sinclair B, Tingley D, Van Zandt T, Vazire S, Watts D, Winship C, Wolpert R, Xie Y, Young C, Zinman J, Johnson V: Redefine statistical significance. Nature Human Behaviour. 2018; 2 (1): 6-10 Publisher Full Text

3. Colquhoun D: An investigation of the false discovery rate and the misinterpretation of $p$ values.R Soc Open Sci. 2014; 1 (3): 140216 PubMed Abstract | Publisher Full Text 4. Senn SJ: Double Jeopardy: Judge Jeffreys upholds the law. 2015. Reference Source 5. Pertile $P$, Forster $M$, Torre D: Optimal Bayesian sequential sampling rules for the economic evaluation of health technologies. Journal of the Royal Statistical Society: Series A (Statistics in Society). 2014; 177 (2): 419-438 Publisher Full Text

6. Jobjörnsson S, Forster M, Pertile P, Burman CF: Late-stage pharmaceutical R\&D and pricing policies under two-stage regulation. J Health Econ. 2016; 50: 298-311 PubMed Abstract | Publisher Full Text

7. Burman C-F: Decision Analysis in Drug Development. In: Dmitrienko A, Chuang-Stein C, Agostino R, eds. Pharmaceutical Statistics Using SAS: A Practical Guide.Cary: SAS Institute. 2007. 385-428

Competing Interests: None 
The benefits of publishing with F1000Research:

- Your article is published within days, with no editorial bias

- You can publish traditional articles, null/negative results, case reports, data notes and more

- The peer review process is transparent and collaborative

- Your article is indexed in PubMed after passing peer review

- Dedicated customer support at every stage

For pre-submission enquiries, contact research@f1000.com 